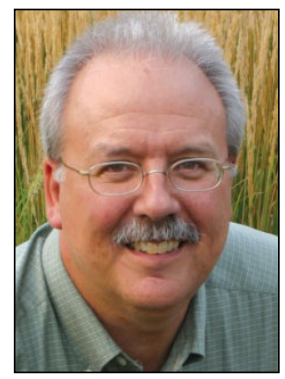

\author{
Metrics fROM THE FIELD \\ Blending insights from research with insights from practice \\ Ken Meter
}

\title{
Co-ops and collective impact
}

Submitted June 2, 2014 / Published online June 18, 2014

Citation: Meter, K. (2014). Co-ops and collective impact. Journal of Agriculture, Food Systems, and

Community Development, 4(3), 11-14. http://dx.doi.org/10.5304/jafscd.2014.043.014

Copyright (C) 2014 by New Leaf Associates, Inc.

$\mathrm{T}$

he nonprofit Cooperative Development

Services (CDS), a cooperative that offers

business consulting services to co-ops, just released an incisive report showing how co-op groceries in the Minneapolis-St. Paul metro area grew over the past 40 years into a US\$180-million commercial cluster (Stockinger \& Gutknecht, 2014). This is strong growth for an upstart sector amidst

Minneapolis-based Ken Meter is one of the most experienced food system analysts in the U.S., having produced nearly 100 state and regional studies of farm and food economies in 36 states, including (with Megan Phillips Goldenberg) Making Small Farms into Big Business, a US\$9.8-million investment plan for local foods commissioned by the state of South Carolina, and a forthcoming review of economic impacts of institutional food purchasing compiled for the Illinois Public Health Institute and the Centers for Disease Control. Meter is now part of a national team devising innovative ways of measuring impacts of food business clusters. established competitors in an often-hostile economic climate. While they still represent only two percent of the region's grocery trade, food coops have built a solid membership base. Their stores define the cutting edge of grocery retailing in the Twin Cities (where I live), and have had a profound influence on the ways groceries are sold here.

The growth of this co-op sector offers important insights into collective impact - an approach that advances the notion that even discrete steps taken by a given initiative will have importance across sectors, creating synergy and larger impacts over time - now widely in use by food initiatives across the U.S.

Let's start with some basic facts from the CDS report. Today there are 15 food co-ops operating 17 stores in the Twin Cities region (with plans underway for adding three new outlets). These coops have enlisted 91,000 members and attract an estimated 50,000 additional shoppers annually. Combined, the stores offer food items from more 
than 300 farmers located within 250 miles $(400 \mathrm{~km})$ of the metro region, who earn an estimated US $\$ 31$ million of farmgate revenue by selling to the coops through various channels. About 60 percent of this revenue was earned by selling directly to each co-op store.

The current generation of Twin Cities food coops originated in 1969, when a small group of rural and urban youth met at a farm in western Wisconsin, seeking a way to both build a market for farmers who wanted to raise organic produce and create healthier food choices for consumers (Meter, 2009). The founders were fully mindful of their predecessors who had launched similar endeavors in the 1800s and the 1930s. Within a few years more than a dozen coops had sprung up. Some ultimately failed as the nowdominant stores expanded.

Most of these stores were launched in low-income neighborhoods, in part because rents were cheaper, but also because hundreds of young people had made their homes in these communities, looking for ways to work alongside their neighbors to improve conditions. Bringing healthier food options to low-income shoppers, it was believed, would help build the neighborhood economy. Yet co-op shopping turned out to elicit limited interest from low-income residents.

Moreover, market pressures persuaded the coop groceries to compete for the attention of more prosperous consumers. Today, CDS describes the co-ops' primary market niche as serving early adapters - those who are quick to embrace new food products and new consumer trends (Meter, 2009). Along the way, co-ops introduced several key innovations to the Twin Cities marketplace: selling organic produce; offering grains, nuts, fairtrade coffee, and other food items in bulk; encouraging the emergence of new growers; and preserving farm identity at the retail shelf. Co-ops also demonstrated that a medium-size store could flourish, when conventional wisdom suggested that only big boxes could be profitable due to economies of size. Co-ops were often first to adapt because they maintained a creative vision and could count on a core of members to invest in this vision (Meter, 2009); all of these pioneering strategies have since been adopted by larger grocery chains.

One of these co-op groceries, The Wedge, also owns the Twin Cities' regional produce wholesaler, Co-op Partners Warehouse. Launched in 1999, this has grown to a US $\$ 20$ million business (Stockinger \& Gutknecht, 2014). CPW primarily conveys produce from organic farms, largely in Minnesota and Wisconsin, to co-op groceries. CPW also cross-docks shipments (that is, CPW handles logistics only, without purchasing the product) for these same growers who sell direct to many of the same stores. This preserves the farmers' ability to command the highest possible price by selling direct to the co-op grocery stores.

For those exploring produce aggregation in their own regions, CPW's history offers an important caution: It took 40 years to get to where these businesses stand today. Two previous warehouses floundered. CDS attributes their folding to the difficulties of competing in a market dominated by large-scale firms. At each stage of the journey, supply and demand had to be balanced, with emerging farms supplying emerging markets, growing somehow in concert with each other.

As someone who helped form several (nongrocery) co-ops40 years ago, I recall meeting with a potential funder and asking for support for one store on the basis that, while the returns from this initiative might be discrete, over time there would be a collective impact. The funder politely let us know that this was too intangible a return for the foundation to consider. Now, in part due to Kania and Kramer's (2011) work on collective impact, several key funders are insisting on a coordinated, collaborative approach. 
This is certainly a step forward, and Kania and Kramer are to be congratulated for popularizing this notion. Yet when I returned to their 2011 paper, I found that the Twin Cities history departed in several ways from the classic model.

Kania and Kramer identify five "conditions of collective impact" (2011):

- Common agenda

- Shared measurement

- Mutually reinforcing activities

- Continuous communication

- Backbone support

Certainly the early co-ops in the Twin Cities held a common vision: they had a sense that only by organizing a new grocery sector could residents actually exert influence over which foods were available to them. Indeed, the profound influence co-ops have held, in my experience, is that local folks began to seize the initiative in making food choices, framing their own vision, in ways that privately owned stores could not accomplish. Cooperators knew instinctively that only if a cluster of cooperating businesses were formed, with supportive infrastructure, would any of the individual firms build a lasting presence.

Yet Kania and Kramer suggest that collective impact requires "a joint approach to solving [a problem] through agreed upon actions" (2013, p. 1). In fact, individual co-ops compete mightily with each other and often have distinct agendas, even if the broad elements of their vision are similar. Each seeks to attract the same customers to join as members, but each is also expanding into new territory. At the same time, membership, with its patronage refunds, also helps build loyalty to the store, reducing competitive pressures.

While the model of collective impact calls for shared measurement, Twin Cities co-ops have struck a more independent path, enjoying a common set of metrics only in the past few years, largely through Stockinger's efforts. Of course, each co-op has similar accounting practices, so business data is relatively comparable. Yet there has been only sparse mutual reporting of metrics.

Nor is it clear that the co-ops always have mutually reinforcing activities. Each differentiates itself from the others, and often their competitive bent reduces any potential synergy. Twin Cities coops are not necessarily in continuous communication, especially at the higher levels of management - though workers in each co-op may well feel a strong affinity for each other as cooperators and some sectorwide gatherings do create mutual awareness.

Co-ops in the Twin Cities do have several organizations to call upon for backbone support. Strong technical resources, including CDS, a cooperative development fund, and a cooperative bank, have been solidified over the past 40 years. Foundations have recently invested in helping expand the co-op grocery sector nationally. Yet these support networks do not coordinate individual co-ops' activities as much as offer specialized assistance toward each store's own goals.

Despite these apparent departures from the model, coops have grown into a vibrant sector that has influenced the likes of Whole Foods and Trader Joe's. This is not to say that Kania and Kramer are wrong, since if one looks closely at their approach, they understand that reality cannot be distilled down into terse statements. In a subsequent paper (2013), they reminded practitioners that their model was meant to foster effective work in emergent settings - when new outcomes emerge that could not have been predicted from initial conditions (definition of "emergence" from Meter, 2006).

I have seen the collective impact model simplified into bullet points and presented as if it were a gospel or a loyalty test. Often this depiction of 
collective impact looks like a recipe selected by a funder that sought highly predictable outcomes in a tightly controlled setting. At such times, once the mantra "collective impact" has been put forward, critical thought may grind to a halt. Kania and Kramer see this is a misuse: they understand theirs is a framework for collaborators to draw upon in order to think critically amidst rapidly changing systems, not a set prescription.

The most common dilutions of the collective impact paradigm, it seems to me, are to assume that one single organization needs to be the "backbone" of a planned effort to achieve collective impacts. Yet Kania and Kramer explicitly state that multiple organizations may share this role. The coop experience bears this out. A second dilution is to assume that collective impact cannot occur unless planned in advance from the top down; once again the co-op history shows otherwise. In the Twin Cities' case, independent boards built separate economic bases at times with conflicting agendas, but with a significant common vision of growing the co-op sector and mutual immersion in a grassroots culture that supported cooperative organizing. In Ontario, by contrast, cooperation among cooperatives was deemed essential (Sumner, et al).

I can imagine, looking back at the past 40 years of co-op groceries, that had funders understood the rich potential for cooperative business to flourish, they might have helped Twin Cities coops adhere more closely to their initial idealistic impulse of providing healthier food to low-income neighbors - a thrust that is unlikely to pay for itself from sales revenues when incomes are disparate. Twin Cities co-ops might have made even stronger impact than they have, but in different ways, and might now be viewed less as gentrifying forces in the very same neighborhoods where they got their start.
Yet this is basically to assert that funders, like scholars and cooperators, need to pay close attention to what is emergent, and support positive steps to the greatest extent possible. This is more of a process of building mutual accountability and of thinking critically together - activities that Kania and Kramer support, yet that are not always part of their followers' actual practice.

\section{References}

Kania, J., \& Kramer, M. (2011, Winter). Collective impact. Stanford Social Innovation Review. Retrieved from http://www.ssireview.org/articles/entry/ collective_impact

Kania, J., \& Kramer, M. (2013, January 21). Embracing emergence: How collective impact addresses complexity. Stanford Social Innovation Review. Retrieved from http://www.ssireview.org/pdf/ Embracing Emergence PDF.pdf

Meter, K. A. (2006). Evaluating farm and food systems in the U.S. In B. Williams \& I. Imam (Eds.). Systems concepts in evaluation: An expert anthology (pp. 141160). Point Reyes Station, California: EdgePress of Inverness.

Meter, K. (2009). Mapping the Minnesota food industry. Minneapolis, Minnesota: Crossroads Resource Center. Available at http://www.crcworks.org/mnfood.pdf

Stockinger, J., \& Gutknecht, D. (2014). The Twin Cities cooperative local food system: $A$ case study and commentary. Cooperative Development Services. Available at http://www.cdsus.coop/new-events/2014-0407/cds-case-study-cooperative-local-foods-system

Sumner, J., McMurtry, J. J., \& Renglich, H. (2014). Leveraging the local: Cooperative food systems and the Local Organic Food Co-ops Network in Ontario, Canada. Journal of Agriculture, Food Systems, and Community Development. Advance online publication. http://dx.doi.org/10.5304/jafscd.2014.043.004 